\title{
HUBUNGAN HIGIENE SANITASI DENGAN KEBERADAAN TELUR CACING PADA LALAPAN KUBIS DI WARUNG MAKAN SARI LAUT SEPANJANG JALAN PERINTIS KEMERDEKAAN KOTA MAKASSAR Haderiah $^{1}$ dan Febriyanti Ramadhani ${ }^{2}$ \\ ${ }^{1.2}$ Poltekkes Kemenkes Makassar \\ febriyantiramadhani1996@gmail.com
}

\begin{abstract}
The implementation of poor sanitation hygiene is often found in food traders such as the lack of application form personal hygiene handlers, the manner of processing, storage and presentation of less good, especially at the time of processing vegetables such as vegetable cabbages so people need to be careful in consuming the vegetable cabbages. This study aims to determine the correlation of sanitation hygiene with the existence of worm eggs in vegetable cabbage at seafood stalls at Perinttis Kemerdekaan street of Makassar city. The type of this research is an analytic survey with an approach cross-sectional approach where independent variables and dependent variables are compared simultaneously to determine the correlation between these variables. The result of this research shows that there is no correlation between personal hygiene of the handlers with the existence of worm eggs ( $\mathrm{sig}=0,683$; $t$ count $=0,411)$, there is correlation with the existence of worm eggs $(\mathrm{sig}=0,038 ; \mathrm{t}$ count $=2,138$ ), there is no correlation the storage food ( $\mathrm{sig}=0,767 ; t$ count $=0,298)$, and there is no correlation with existence of worm egg $(\mathrm{sig}=0,785 ; t$ count $=0,275)$. This research concludes that there is a correlation of processing with the existence of worm eggs, and there is personal hygiene not the correlation of the handlers, the storage, and serving food with the existence of worm eggs in vegetable cabbage. Advice for food handlers to maintain personal hygiene, cleanliness of places, equipment, and vegetable cabbage at the time of processing.
\end{abstract}

Keywords: Personal hygiene, food sanitation, worm eggs, vegetable cabbage.

\section{ABSTRAK}

Penerapan higiene sanitasi yang buruk sering ditemukan pada pedagang makanan seperti kurangnya penerapan higiene personal penjamah, cara pengolahan, penyimpanan dan penyajian yang kurang baik terutama pada saat akan mengolah sayuran seperti lalapan sehingga masyarakat perlu berhati-hati dalam mengkonsumsi lalapan.Tujuan dari penelitian ini adalah untuk mengetahui hubungan higiene sanitasi dengan keberadaan telur cacing pada lalapan kubis di warung makan sari laut sepanjang jalan Perintis Kemerdekaan kota Makassar. Jenis penelitian yang digunakan adalah survei analitik dengan pendekatan cross sectional dimana variabel bebas dan variabel terikat dibandingkan secara bersamaan untuk mengetahui hubungan antara variable variable tersebut. Hasil penelitian ini menunjukkan tidak ada hubungan higiene personal penjamah dengan keberadaan telur cacing ( $\mathrm{sig}=0,683 ; \mathrm{t}$ hitung $=0,411$ ), ada hubungan pengolahan dengan keberadaan telur cacing $(\mathrm{sig}=0,038 ; \mathrm{t}$ hitung $=2,138)$, tidak ada hubungan penyimpanan makanan dengan keberadaan telur cacing $(\operatorname{sig}=0,767$; hitung $=0,298)$, dan tidak ada hubungan penyajian dengan keberadaan telur cacing ( $\mathrm{sig}=0,785 ; \mathrm{t}$ hitung $=0,275$ ). Kesimpulan dalam penelitian ini adalah adanya hubungan pengolahan dengan keberadaan telur cacing, dan tidak ada hubungan higiene personal penjamah, penyimpanan, dan penyajian makanan dengan keberadaan telur cacing pada lalapan kubis. Saran bagi penjamah makanan agar menjaga kebersihan diri, kebersihan tempat, peralatan dan bahan sayuran kubis pada saat pengolahan.

Kata Kunci : Higiene personal, sanitasi makanan, telur cacing, lalapan kubis.

\section{PENDAHULUAN}

Peningkatan

jumlah penduduk dan pembangunan di Indonesia, pemerintah membuat konsep untuk program tujuan pembangunan berkelanjutan 2030 dalam Sustainable Development Goals (SDGs). Dalam mempercepat pencapaian MDGs, pemerintah menetapkan STBM sebagai kebijakan nasional untuk mewujudkan perilaku masyarakat yang higiene dan saniter dengan harapan pada tahun 2025, Indonesia bisa mencapai sanitasi total untuk seluruh masyarakat, sebagaimana tercantum dalam Rencana Pembangunan Jangka Panjang Nasional (RPJPN) Indonesia. Konsep SDGs terdapat 4 tujuan yang menjadi perhatian khusus pada sektor kesehatan sebagai outcome pembangunan berkelanjutan, khususnya pada tujuan ke-6 yaitu pencapaian sanitasi dan higiene yang cukup dan merata bagi semua orang (Republik Indonesia, 2015).
Penerapan higiene sanitasi yang buruk dapat menciptakan kondisi yang tidak sehat dan hal ini sering ditemukan pada pedagang makanan seperti kurangnya penerapan higiene personal penjamah, cara pengolahan, penyimpanan dan penyajian yang kurang baik terutama pada saat akan mengolah sayuran seperti lalapan sehingga masyarakat perlu berhati - hati dalam mengkonsumsi lalapan yang kurang baik dalam pengolahannya (Yulia, 2016).

Sayuran yang rentan terkontaminasi parasit yaitu kubis, dengan kondisi daun yang bergelombang dan berbentuk bulat utuh sehingga memungkinkan telur cacing menetap di dalamnya meskipun telah dicuci, selain itu penanamannya yang langsung bersentuhan dengan tanah dan harus menggunakan tanah yang mengandung bahan organic memungkinkan menempelnya parasit usus/cacing. (Lamri, 2016). 
Jurnal Sulolipu : Media Komunikasi Sivitas Akademika dan Masyarakat

Vol. 18 No 22018

e-issn : 2622-6960, p-issn : 0854-624X

Berdasarkan data dari World Health Organization (WHO) pada tahun 2012 lebih dari 1.5 miliar orang atau $24 \%$ dari populasi dunia terinfeksi Soil Transmitted Helminths (STH). Di Indonesia sendiri infeksi kecacingan masih relatif tinggi pada tahun 2011, yaitu sebesar $28 \%$, survei pada anak sekolah dasar menunjukkan prevalensi antara $0-76.67 \%$ (Andi, 2016).

Berdasarkan data dari Dinas Kesehatan Provinsi Sulawesi Selatan dalam Andi (2016) bahwa penderita kecacingan di Sulawesi Selatan masih terbilang banyak dan disetiap tahunnya mengalami peningkatan yaitu pada tahun, 2012 (9.476 kasus), 2013 (12.949 kasus), 2014 (13.375 kasus). Selanjutnya berdasarkan data dari Dinas Kesehatan Kabupaten/Kota bahwa kota Makassar menjadi kota tertinggi penderita kasus kecacingan. Jumlah penderita kecacingan di kota Makassar mengalami peningkatan dari tahun 2013 (3.226 kasus), 2014 (3.266 kasus), 2015 (3.270 kasus).

Berdasarkan observasi awal yang peneliti lakukan pada tanggal 13 Desember 2017 di jalan Perintis Kemerdekaan kota Makassar didapatkan gambaran pengolahan. Dan dilakukannya uji pendahuluan pada tanggal 14 Desember 2017, terhadap identifikasi telur cacing pada lalapan kubis yang dijual di warung makan sari laut di sepanjang jalan Perintis Kemerdekaan ditemukan adanya kontaminasi telur cacing. Dari 5 warung makan, diambil 5 sampel untuk diperiksa. 4 sampel lalapan positif telur cacing dan 1 sampel negatif telur cacing.

\section{BAHAN DAN METODE}

\section{Lokasi Penelitian}

Lokasi pengambilan sampel lalapan kubis adalah di warung makan sari laut sepanjang jalan Perintis Kemerdekaan kota Makassar.

\section{Variabel Penelitian}

Variabel bebas dalam penelitian ini yaitu higiene personal penjamah, pengolahan makanan, penyimpanan makanan dan penyajian makanan. Variabel terikat yang dalam hal ini adalah keberadaan telur cacing pada lalapan kubis. Dan variabel pengganggu dalam hal ini pemilihan bahan makanan, penyimpanan bahan makanan, dan pengangkutan makanan.

\section{Populasi dan Sampel}

Populasi dalam penelitian ini adalah seluruh warung makan sari laut di sepanjang jalan Perintis Kemerdekaan kota Makassar dengan jumlah 50 populasi dan sampel yaitu seluruh warung makan sari laut yang berjumlah 50 sampel.

\section{Pengumpulan Data}

a. Data Primer

Data primer diperoleh dari hasil observasi langsung menggunakan lembar survei dan observasi, serta hasil pemeriksaan telur cacing di Laboratorium Parasitologi.

b. Data Sekunder

Data sekunder diperoleh melalui penelusuran kepustakaan berupa referensi hasil penelitian sebelumnya, jurnal, artikel, maupun laporan pemerintah yang terkait seperti Dinas Kesehatan Provinsi dan Kota.

\section{Analisis Data}

Data penelitian dianalisis dengan analisis Univariat dan Bivariat, Menggunakan uji statistik berupa Uji T-test dengan Regresi Linear Berganda.

\section{HASIL PENELITIAN}

Hubungan Higiene Personal Penjamah dengan Keberadaan Telur Cacing pada Lalapan Kubis

Tabel 1

Hubungan Higiene Personal Penjamah dengan Keberadaan Telur Cacing

\begin{tabular}{|c|c|c|c|c|c|c|c|c|c|}
\hline \multirow{3}{*}{$\begin{array}{l}\text { Higiene } \\
\text { Personal } \\
\text { Penjamah }\end{array}$} & \multicolumn{6}{|c|}{ Keberadaan Telur Cacing } & \multirow{3}{*}{$\alpha$} & \multirow{3}{*}{$\mathrm{t}$} & \multirow{3}{*}{ sig } \\
\hline & \multicolumn{2}{|c|}{ Positif } & \multicolumn{2}{|c|}{ Negatif } & \multirow{2}{*}{$\begin{array}{c}\text { Tot } \\
\text { al }\end{array}$} & \multirow{2}{*}{$\%$} & & & \\
\hline & $\Sigma$ & $\%$ & $\Sigma$ & $\%$ & & & & & \\
\hline $\begin{array}{l}\text { Tidak } \\
\text { Memenuh } \\
\text { i Syarat }\end{array}$ & 45 & 90 & 5 & 10 & 50 & 10 & & & \\
\hline $\begin{array}{l}\text { Memenuh } \\
\text { i Syarat }\end{array}$ & 0 & 0 & 0 & 0 & 0 & 0 & $\begin{array}{c}0,0 \\
5\end{array}$ & $\begin{array}{c}0,4 \\
11\end{array}$ & $\begin{array}{c}0,6 \\
83\end{array}$ \\
\hline Total & 5 & 10 & 45 & 90 & 50 & $\begin{array}{c}10 \\
0\end{array}$ & & & \\
\hline
\end{tabular}

Sumber: Data Primer, 2018

Berdasarkan tabel 1 dapat diperoleh informasi bahwa dari 50 warung makan yang tidak memenuhi syarat yaitu semua responden sebanyak 50 warung makan dan dari yang tidak memenuhi syarat tersebut terdapat 45 sampel (90 $\%$ ) yang positif telur cacing dan sebanyak 5 sampel lalapan kubis (10\%) yang negatif telur cacing. Sedangkan dari 50 warung makan untuk higiene personal penjamah yang memenuhi syarat 0 warung makan. Setelah dilakukan uji statistik berupa Uji Regresi Linier Berganda diketahui nilai sig $=0,683>\alpha=0,05$ dan nilai $t$ hitung $=0,411<t$ tabel $=2,014$, sehingga Ho diterima. 
Jurnal Sulolipu : Media Komunikasi Sivitas Akademika dan Masyarakat

Vol. 18 No 22018

e-issn : 2622-6960, p-issn : 0854-624X

Tabel 2

Hubungan Pengolahan Makanan dengan Keberadaan Telur Cacing pada Lalapan Kubis

\begin{tabular}{|c|c|c|c|c|c|c|c|c|c|}
\hline \multirow{3}{*}{$\begin{array}{l}\text { Pengolah } \\
\text { an } \\
\text { Makanan }\end{array}$} & \multicolumn{6}{|c|}{ Keberadaan Telur Cacing } & \multirow{3}{*}{$\alpha$} & \multirow{3}{*}{$\mathrm{t}$} & \multirow{3}{*}{ sig } \\
\hline & \multicolumn{2}{|c|}{ Positif } & \multicolumn{2}{|c|}{ Negatif } & \multirow{2}{*}{$\begin{array}{c}\text { Tot } \\
\text { al }\end{array}$} & \multirow{2}{*}{$\%$} & & & \\
\hline & $\Sigma$ & $\%$ & $\Sigma$ & $\%$ & & & & & \\
\hline Tidak & & & & & & & & & \\
\hline $\begin{array}{l}\text { Memenu } \\
\text { hi Syarat }\end{array}$ & 34 & 97,1 & 1 & 2,9 & 35 & 100 & & & \\
\hline $\begin{array}{l}\text { Memenu } \\
\text { hi Syarat }\end{array}$ & 11 & 73,3 & 4 & $\begin{array}{l}26, \\
7\end{array}$ & 15 & 100 & $\begin{array}{c}0,0 \\
5\end{array}$ & $\begin{array}{l}2,1 \\
38\end{array}$ & $\begin{array}{c}03 \\
8\end{array}$ \\
\hline Total & 5 & 10 & $\begin{array}{l}4 \\
5\end{array}$ & 90 & 50 & 100 & & & \\
\hline
\end{tabular}

Sumber: Data Primer, 2018

Pada tabel 2 menunjukkan bahwa dari 35 warung makan yang tidak memenuhi syarat, terdapat 34 sampel $(97,1 \%)$ yang positif terdapat telur cacing dan sebanyak 1 sampel (2,9\%) yang negatif telur cacing. Sedangkan dari 15 warung makan untuk pengolahan makanan yang memenuhi syarat, terdapat 11 sampel $(73,3 \%)$ yang positif terdapat telur cacing dan sebanyak 4 sampel lalapan kubis $(26,7 \%)$ negatif telur cacing. Setelah dilakukan uji statistik berupa Uji Regresi Linier Berganda diketahui nilai sig $=0,038<\alpha=0,05$ dan nilai $t$ hitung $=2,138>\mathrm{t}$ tabel $=2,014$, sehingga dapat disimpulkan bahwa Ho ditolak.

Tabel 3

Hubungan Penyimpanan Makanan dengan Keberadaan Telur Cacing pada Lalapan Kubis

\begin{tabular}{|c|c|c|c|c|c|c|c|c|c|}
\hline \multirow{3}{*}{$\begin{array}{c}\text { Penyimpa } \\
\text { nan } \\
\text { Makanan }\end{array}$} & \multicolumn{6}{|c|}{ Keberadaan Telur Cacing } & \multirow{3}{*}{$\alpha$} & \multirow{3}{*}{$\mathrm{t}$} & \multirow{3}{*}{ sig } \\
\hline & \multicolumn{2}{|c|}{ Positif } & \multicolumn{2}{|c|}{ Negatif } & \multirow{2}{*}{$\begin{array}{l}\text { Tot } \\
\text { al }\end{array}$} & \multirow{2}{*}{$\%$} & & & \\
\hline & $\sum$ & $\%$ & $\Sigma$ & $\%$ & & & & & \\
\hline $\begin{array}{l}\text { Tidak } \\
\text { Memenuhi } \\
\text { Syarat }\end{array}$ & 36 & $\begin{array}{c}92, \\
3\end{array}$ & 3 & 7,7 & 39 & $\begin{array}{c}10 \\
0\end{array}$ & & & \\
\hline $\begin{array}{l}\text { Memenuhi } \\
\text { Syarat }\end{array}$ & 9 & $\begin{array}{c}81, \\
8\end{array}$ & 2 & $\begin{array}{c}18, \\
8\end{array}$ & 11 & $\begin{array}{c}10 \\
0\end{array}$ & $\begin{array}{c}0,0 \\
5\end{array}$ & $\begin{array}{l}0,2 \\
98\end{array}$ & $\begin{array}{l}0,7 \\
67\end{array}$ \\
\hline Total & 5 & 10 & 45 & 90 & 50 & $\begin{array}{c}10 \\
0\end{array}$ & & & \\
\hline
\end{tabular}

Sumber: Data Primer,2018

Pada tabel 3 menunjukkan bahwa dari 39 warung makan yang tidak memenuhi syarat, terdapat 36 sampel $(92,3 \%)$ yang positif terdapat telur cacing dan sebanyak 3 sampel $(7,7 \%)$ yang negatif telur cacing. Sedangkan 11 warung makan untuk penyimpanan makanan yang memenuhi syarat, terdapat 9 sampel $(81,8 \%)$ yang positif terdapat telur cacing dan sebanyak 2 sampel lalapan kubis DDC(18,2 \%) negatif telur cacing. Setelah dilakukan uji analisis dengan Regresi Linier Berganda diketahui nilai sig $=0,767>\alpha=0,05$ dan nilai $t$ hitung $=0,298<\mathrm{t}$ tabel $=2,014$, sehingga dapat disimpulkan bahwa Ho diterima.
Tabel 4

Hubungan Penyajian Makanan dengan Keberadaan Telur Cacing pada Lalapan Kubis

\begin{tabular}{|c|c|c|c|c|c|c|c|c|c|}
\hline \multirow{3}{*}{$\begin{array}{c}\text { Penyajia } \\
n \\
\text { Makanan }\end{array}$} & \multicolumn{6}{|c|}{ Keberadaan Telur Cacing } & \multirow{3}{*}{$\alpha$} & \multirow{3}{*}{$\mathrm{T}$} & \multirow{3}{*}{ sig } \\
\hline & \multicolumn{2}{|c|}{ Ada } & \multicolumn{2}{|c|}{$\begin{array}{l}\text { Tidak } \\
\text { Ada }\end{array}$} & \multirow{2}{*}{$\begin{array}{c}\text { Tot } \\
\text { al }\end{array}$} & \multirow[t]{2}{*}{$\%$} & & & \\
\hline & $\sum$ & $\%$ & $\sum$ & $\%$ & & & & & \\
\hline $\begin{array}{l}\text { Tidak } \\
\text { Memen } \\
\text { uhi } \\
\text { Syarat }\end{array}$ & $\begin{array}{l}3 \\
8\end{array}$ & $\begin{array}{c}92, \\
7\end{array}$ & 3 & 7,3 & 41 & $\begin{array}{c}10 \\
0\end{array}$ & \multirow{3}{*}{$\begin{array}{c}0,0 \\
5\end{array}$} & \multirow{3}{*}{$\begin{array}{l}0,2 \\
75\end{array}$} & \multirow{3}{*}{$\begin{array}{l}0,7 \\
85\end{array}$} \\
\hline $\begin{array}{l}\text { Memen } \\
\text { uhi } \\
\text { Syarat }\end{array}$ & 7 & $\begin{array}{c}77, \\
8\end{array}$ & 2 & $\begin{array}{c}22, \\
2\end{array}$ & 9 & $\begin{array}{c}10 \\
0\end{array}$ & & & \\
\hline Total & 5 & 10 & $\begin{array}{l}4 \\
5\end{array}$ & 90 & 50 & $\begin{array}{c}10 \\
0\end{array}$ & & & \\
\hline
\end{tabular}

Sumber: Data Primer,2018

Pada tabel 5.9 menunjukkan bahwa dari 41 warung makan yang tidak memenuhi syarat, terdapat 38 sampel $(92,7 \%)$ yang positif terdapat telur cacing dan sebanyak 3 sampel $(7,3 \%)$ yang negatif telur cacing. Sedangkan dari 9 warung makan untuk penyajian makanan yang memenuhi syarat, terdapat 7 sampel $(77,8 \%)$ yang positif terdapat telur cacing dan sebanyak 2 sampel lalapan kubis $(22,2 \%)$ negatif telur cacing. Setelah dilakukan uji statistik berupa Uji Regresi Linier Berganda diketahui nilai sig $=0,785>\alpha=0,05$ dan nilai $t$ hitung $=0,275<\mathrm{t}$ tabel $=2,014$, sehingga dapat disimpulkan bahwa Ho diterima.

\section{PEMBAHASAN}

Dalam pembahasan ini penulis akan menguraikan analisa hasil penelitian sebagai berikut:

\section{Hubungan Higiene Personal Penjamah dengan Keberadaan Telur Cacing pada Lalapan Kubis}

Berdasarkan analisis statistik berupa Uji Regresi Linier Berganda diketahui nilai sig = $0,683>\alpha=0,05$ dan nilai $\mathrm{t}$ hitung $=0,411<\mathrm{t}$ tabel $=2,014$, sehingga dapat disimpulkan bahwa Ho diterima yang berarti tidak ada hubungan antara higiene personal penjamah dengan keberadaan telur cacing pada lalapan kubis.

Penelitian ini sejalan dengan penelitian yang dilakukan oleh Umi (2018) tentang Hubungan Higiene Personal Pedagang dan Sanitasi Makanan dengan Keberadaan Telur Cacing Soil Transmitted Helminths (STH) pada Lalapan Penyetan di Pujasera Simpanglima Kota Semarang. Dimana didapatkan hasil tidak ada hubungan higiene personal pedagang dengan keberadaan telur cacing Soil 
Jurnal Sulolipu : Media Komunikasi Sivitas Akademika dan Masyarakat

Vol. 18 No 22018

e-issn : 2622-6960, p-issn : 0854-624X

Transmitted Helminths (STH) pada lalapan penyetan.

Berdasarkan hasil observasi yang telah dilakukan ditemukan pada item pernyataan untuk penjamah yang mencuci tangan sebelum mengolah makanan yaitu $50 \%$ dan mencuci tangan sesudah mengolah makanan $48 \%$ serta menggunakan sabun sebanyak $54 \%$. Dari hasil yang didapatkan tersebut dapat diketahui bahwa sebagian besar penjamah di warung makan sari laut telah menjaga kebersihan tangannya hal inilah yang menjadi pemicu utama tidak adanya hubungan higiene personal penjamah dengan keberadaan telur cacing pada lalapan kubis.

Selain menjaga kebersihan tangan dengan mencuci tangan sebelum dan sesudah mengolah makanan, kebiasaan tangan dari penjamah makanan ikut andil dalam menyebabkan tidak adanya hubungan antara higiene penjamah dengan keberadaan telur cacing pada lalapan kubis. Kebiasaan yang dilakukan oleh tangan berhubungan dengan pergerakan - pergerakan yang sering dilakukan penjamah diluar dari kesadaran seperti mengorek, menggaruk anggota badan antara lain telinga, hidung, kepala, tangan, kaki dan anggota badan lainnya. Berdasarkan hasil observasi terkait item pernyataan untuk kebiasaan jorok dari pergerakan tangan penjamah menunjukkan bahwa $44 \%$ penjamah telah menghindari kebiasaan jorok dari pergerakan - pergerakan tangan yang dapat terjadi diluar dari kesadaran, dengan itu penjamah lebih meningkatkan konsentrasi dalam mengolah makanan sehingga tidak melakukan pergerakan - pergerakan lain yang dapat menyebabkan tangan terkontaminasi oleh anggota badan lainnya yang kotor. Karena diketahui tangan yang kotor dapat menimbulkan adanya kontaminasi telur cacing ke dalam makanan salah satunya yaitu penularan telur cacing Ascaries lumbricoides, penularan telur cacing Ascaries lumbricoides biasanya terjadi secara oral ketika tangan yang kotor menyentuh makanan dan masuk ke dalam mulut (Suhintam, 2013). Maka dari itu ada tidaknya telur cacing pada makanan sangat ditentukan oleh kebersihan tangan penjamah makanan itu sendiri.

\section{Hubungan Pengolahan Makanan dengan Keberadaan Telur Cacing pada Lalapan Kubis}

Berdasarkan analisis statistik berupa Uji Regresi Linier Berganda diketahui nilai sig = $0,038<\alpha=0,05$ dan nilai $\mathrm{t}$ hitung $=2,138>\mathrm{t}$ tabel $=2,014$, sehingga dapat disimpulkan bahwa Ho ditolak yang berarti ada hubungan antara pengolahan makanan dengan keberadaan telur cacing pada lalapan kubis.

Penelitian ini sejalan dengan penelitian yang dilakukan oleh Umi (2018) tentang Hubungan Higiene Personal Pedagang dan Sanitasi Makanan dengan Keberadaan Telur Cacing Soil Transmitted Helminths (STH) pada Lalapan Penyetan di Pujasera Simpanglima Kota Semarang. Dengan hasil analisis statistik menunjukkan ada hubungan sanitasi makanan dengan keberadaan telur cacing Soil Transmitted Helminths pada lalapan kubis dengan hasil uji Chi Square menunjukkan nilai $p$ $=0,004<\alpha=0,05$.

Dalam penelitian yang dilakukan oleh Yulia (2016) menyebutkan bahwa peranan peralatan makan dan masak dalam penyehatan makanan khususnya pada saat pengolahan makanan sangat penting karena merupakan bagian yang tidak terpisahkan dari prinsip prinsip penyehatan makanan. Dan menjaga kebersihan peralatan makan dan masak, telah membantu mencegah terjadinya pencemaran atau kontaminasi makanan yang dapat terjadi karena peralatan yang digunakan. Dari pendapat tesebut dapat dihubungkan dengan hasil observasi yang telah dilakukan pada warung - warung makan sari laut dengan item pernyataan terkait kondisi peralatan masak dan kondisi kebersihan bahan sayuran dengan diketahuinya $86 \%$ warung makan tidak memperhatikan kondisi kebersihan peralatan masak dan kebersihan sayuran kubis sebelum diolah. Kondisi yang ada tersebut bertolakbelakang dengan pendapat yang dikemukakan oleh Yulia (2016), sehingga hal inilah yang menimbulkan adanya peluang terjadinya kontaminasi telur cacing pada lalapan kubis. Dan pada item pernyataan tersebut dapat menunjukkan bahwa adanya hubungan pada proses pengolahan dengan keberadaan telur cacing pada lalapan kubis.

Kontaminasi pada lalapan kubis tersebut terjadi pada saat proses pencucian sayuran kubis dalam bentuk bulat utuh dan tidak menggunakan air yang mengalir sehingga memungkinkan masih menetapnya telur cacing. 
Jurnal Sulolipu : Media Komunikasi Sivitas Akademika dan Masyarakat

Vol. 18 No 22018

e-issn : 2622-6960, p-issn : 0854-624X

Adapun penjamah dalam mengolahan sayuran kubis tidak melakukan proses pencucian sayuran kubis sebelum dimasak. Selain itu, tempat pengolahan makanan dilakukan di tenda jualan yang berada di pinggir jalan yang dapat menjadi peluang terjadinya kontaminasi oleh debu yang mengandung telur cacing yang diterbangkan oleh angin.

3. Hubungan Penyimpanan Makanan dengan Keberadaan Telur Cacing pada Lalapan Kubis

Berdasarkan analisis statistik berupa Uji Regresi Linier Berganda diketahui nilai sig = $0,767>\alpha=0,05$ dan nilai $\mathrm{t}$ hitung $=0,298<\mathrm{t}$ tabel $=2,014$, sehingga dapat disimpulkan bahwa Ho diterima yang berarti tidak ada hubungan antara penyimpanan makanan dengan keberadaan telur cacing pada lalapan kubis.

Tidak adanya hubungan pada variabel ini disebabkan karena penjamah pada warung makan telah menerapkan prinsip FIFO dengan baik. Dimana pada hasil observasi ditemukan $90 \%$ warung makan yang menerapkan sistem FIFO. Selain itu cara penyimpanan makanan sesuai dengan jenisnya ditemukan sebanyak 70 $\%$ makanan yang telah diolah tidak dicampur dengan bahan makanan mentah, dengan menerapkan kedua prinsip tersebut penjamah warung makan sari laut telah meminimalisir adanya kemungkinan kontaminasi telur cacing pada lalapan kubis dan dapat memperpanjang masa simpan dari lalapan kubis tersbut. Faktor lain yang menyebabkan tidak terdapatnya hubungan penyimpanan makanan dengan keberadaan telur cacing pada lalapan kubis disebabkan adanya item pada variabel penyimpanan makanan yang memenuhi syarat meskipun dihasil pemeriksaan ada yang menunjukkan positif keberadaan telur cacing.

4. Hubungan Penyajian Makanan dengan Keberadaan Telur Cacing pada Lalapan Kubis

Berdasarkan analisis statistik berupa $U \mathrm{Ji}$ Regresi Linier Berganda diketahui nilai sig = $0,785>\alpha=0,05$ dan nilai $\mathrm{t}$ hitung $=0,275<\mathrm{t}$ tabel $=2,014$, sehingga dapat disimpulkan bahwa Ho diterima yang berarti tidak ada hubungan antara penyajian makanan dengan keberadaan telur cacing pada lalapan kubis.

Upaya penyajian yang baik ini telah dilakukan oleh penjamah di warung - warung makan sari laut yang dimana hal tersebut diketahui dari hasil observasi, pedagang yang menggunakan peralatan yang bersih dalam penyajian yaitu 41 warung makan dengan persentase $(82 \%)$ dan penjamah yang tidak kontak langsung dengan makanan pada saat penyajian yaitu 39 warung makan dengan persentase (78 \%). Cara penyajian dengan menggunakan peralatan yang bersih tersebut dapat menjadi penunjang mencegah makanan tidak terkontaminasi telur cacing, baik dari peralatan itu sendiri maupun dari tangan penjamah jika menyentuh bagian peralatan yang kontak langsung dengan makanan maupun mulut, hal ini dikarenakan transmisi telur cacing dapat terjadi melalui tangan atau kuku yang mengandung telur cacing kemudian masuk ke mulut melalui makanan (Yuni, 2017). Sekaitan dengan hipotesis yang menunjukkan bahwa tidak adanya hubungan penyajian dengan keberadaan telur cacing pada lalapan kubis disebabkan banyaknya warung makan yang memenuhi syarat pada item pernyataan ini, meskipun dihasil pemeriksaan laboratorium menunjukkan positif telur cacing. Adanya telur cacing pada beberapa sampel lalapan kubis ini dapat disebabkan oleh beberapa faktor lain dari berbagai variabel yang ada.

\section{KESIMPULAN DAN SARAN}

\section{Kesimpulan}

a. Tidak ada hubungan higiene personal penjamah dengan keberadaan telur cacing pada lalapan kubis nilai sig $=$ $0,683>\alpha=0,05$ dan nilai t hitung $=0,411$ $<\mathrm{t}$ tabel $=2,014$.

b. Ada hubungan pengolahan makanan dengan keberadaan telur cacing pada lalapan kubis nilai sig $=0,038<\alpha=0,05$ dan nilai $\mathrm{t}$ hitung $=2,138>\mathrm{t}$ tabel $=$ 2,014 .

c. Tidak ada hubungan penyimpanan makanan dengan keberadaan telur cacing pada lalapan kubis nilai sig $=$ $0,767>\alpha=0,05$ dan nilai t hitung $=0,298$ $<\mathrm{t}$ tabel $=2,014$.

d. Tidak ada hubungan penyajian makanan dengan keberadaan telur cacing pada lalapan kubis nilai sig $=0,785>\alpha=0,05$ dan nilai $\mathrm{t}$ hitung $=0,275<\mathrm{t}$ tabel $=$ 2,014 .

\section{Saran}

a. Bagi penjamah makanan agar menjaga kebersihan diri seperti kebersihan tangan sebelum dan sesudah mengolah makanan, menjaga kebersihan tempat, peralatan dan bahan sayuran kubis pada saat pengolahan, dan selalu mengontrol suhu penyimpanan agar tetap ideal. 
Jurnal Sulolipu : Media Komunikasi Sivitas Akademika dan Masyarakat

Vol. 18 No 22018

e-issn : 2622-6960, p-issn : 0854-624X

b. Bagi masyarakat diharapkan mampu memilih dan mengkonsumsi makanan khususnya makanan jajanan di pinggir jalan yang aman, dengan melihat

kebersihan penjamah itu sendiri dan cara mengolah makanan yang disajikan

\section{DAFTAR PUSTAKA}

Andi Tri Rezki Amaliah dan Azriful. 2016. Distribusi Spasial Kasus Kecacingan (Ascaris lumbricoides) Terhadap Personal Higiene Anak Balita Di Pulau Kodingareng Kecamatan Ujung Tanah Kota Makassar Tahun 2016. Higiene Jurnal Kesehatan Lingkungan. 2 (2): 75. (online). http://www.journal.uin-alauddin.ac.id. Diakses 17 Oktober 2017.

Cecep Dani Sucipto. 2015. Keamanan Pangan Untuk Kesehatan Manusia. Yogyakarta: Gosyen Publishing.

Koes Irianto. 2011. Parasitologi. Bandung: CV. Yrama Widya.

Laila Nailul Muna. 2016. Analisis Pengetahuan, Sikap, Dan Tindakan Praktik Tentang Keamanan Pangan Penjamah Makanan Kantin DiDalam Kampus Institut Pertanian Bogor. Skripsi, Fakultas Ekologi Manusia Institus Pertanian Bogor. Bogor. (online). https://repository.ipb.ac.id>handle. Diakses 23 Juni 2018.

Lamri. 2016. Pemeriksaan Telur Cacing Nematoda Usus Lalapan Mentah Di Warung Makan Di Samarinda. Mahakam Medical Laboratory Technology Journal. 1 (1): 3. (online). http://ejournalanalis.poltekkes-kaltim.ac.id. Diakses 26 September 2017.

Niluh Ita Pasyanti, Fitria Saftarina, dan Evi Kurniawaty. 2015. Pengaruh Promosi Kesehatan Terhadap Pengetahuan Siswa Kelas 4,5 dan 6 Dalam Upaya Pencegahan Kecacingan Di SDN 2 Keteguhan Teluk Betung Barat. Jurnal Majority. 4 (5): 36. (online). http://juke.kedokteran.unila.ac.id. Diakses 15 Oktober 2017.

Republik Indonesia. 2015. Keputusan Menteri Kesehatan Republik Indonesia Nomor 97 tentang Kesehatan Dalam Kerangka SDGs.

Suhintam Pusarawati, dkk. 2013. Atlas Parasitologi Kedokteran. Jakarta: Buku Kedokteran EGC.

Umar Z. 2008. Perilaku Cuci Tangan Sebelum Makan dan Kecacingan pada Murid SD di Kabupaten Pesisir Selatan Sumatera Barat. Jurnal Kesehatan Masyarakat Nasional. 2 (6): 252. (online). http://media.nelti.com. Diakses 9 Juli 2018.

Umi Alfiani, dkk. 2018. Hubungan Higiene Personal Pedagang Dan Sanitasi Makanan Dengan Keberadaan Telur Cacing STH Pada lalapan Penyetan Di Pujasera Simpanglima Kota Semarang. Jurnal Kesehatan Masyarakat. 6 (1): 687-693. (online). http://ejournal3.undip.ac.id/. Diakses 23 Juni 2018.

Widiyanto Joko. 2012. SPSS For Windows. Badan Penerbit-FKIP Universitas Muhammadiyah Surakarta. Surakarta. (online). http://www.konsistensi.com. Diakses 27 Februari 2018.

Yuni Febriyanti. 2017. Identifikasi Soil Transmiteed Helminths (STH) Pada Lalapan Kubis (Brassica oleracea var capitata) Dan Kemangi (Ocimum tenuiflorum) Di Warung Makan Kecamatan Selaparang Kota Mataram. Jurnal Penelitian dan Kajian IImiah Kesehatan. 3 (2): 83. (online). www.lppm-mfh.com. Diakses 23 Juni 2018.

Yulia. 2016. Higiene Sanitasi Makanan, Minuman Dan Sarana Sanitasi Terhadap Angka Kuman Peralatan Makan Dan Minum Pada Kantin. Jurnal Vokasi Kesehatan. 2 (1): 56. (online). http://ejournal.poltekkes-pontianak.ac.id. Diakses 17 November 2017. 